\title{
Balanço hídrico e de nitrogênio em eqüinos alimentados com feno de alfafa, feno de tifton-85 e concentrado
}

\author{
Water and nitrogen balance in horses fed with alfafa hay, tifton-85 \\ hay and concentrate
}

\author{
Anilce de Araújo Brêtas, ${ }^{*}$ Fernando Queiroz de Almeida, ${ }^{* *}$ Antônio Assis Vieira, ${ }^{* *}$ Maria Izabel Vieira de Almeida, ${ }^{* *}$ \\ Róbson Ricardo Moreira Pimentel, ${ }^{*}$ Vinícius Pimentel Silva, ${ }^{* * *}$ Tiago Marques dos Santos, ${ }^{* * * * *}$ \\ Fernanda Nascimento de Godoi, ${ }^{* * * *}$ Leandro Galzerano*****
}

\begin{abstract}
Resumo
O presente trabalho foi realizado com o objetivo de avaliar o balanço hídrico e de nitrogênio em eqüinos. Foram utilizados quatro eqüinos mestiços, com a idade de 30 meses e pesando em média $200 \pm 2,2 \mathrm{~kg}$. Os eqüinos foram alimentados com quatro dietas: Dieta I - feno de tifton-85; Dieta II - feno de tifton-85 e feno de alfafa; Dieta III - feno de tifton-85, feno de alfafa e ração concentrada; e Dieta IV - feno de tifton-85 e ração concentrada. Nos eqüinos alimentados com a dieta composta por feno de tifton-85 e feno de alfafa, ocorreu maior excreção de água nas fezes. Entretanto, os valores do balanço hídrico foram semelhantes indicando que a manipulação da dieta pode alterar a via de excreção de água sem afetar o balanço hídrico dos animais. Não foram observadas diferenças $(P>0,05)$ nas quantidades de compostos nitrogenados absorvidos e retidos, indicando o ajuste no consumo da proteína dietética entre as diferentes dietas.
\end{abstract}

Palavras-chave: alimentos, dietas, compostos nitrogenados.

\begin{abstract}
The present paper was carried out to evaluate water and nitrogen balance in horses. Four crossbreed horses with 30 months age and weight of $200 \pm 2.2 \mathrm{~kg}$ were used. Horses were fed with four diets: Diet I - tifton-85 hay; Diet II - tifton-85 hay and alfafa hay; Diet III - tifton-85 hay, alfafa hay and concentrate; Diet IV - tifton-85 hay and concentrate. Horses fed diets with tifton- 85 hay and alfafa hay presented high water excretion in feces but water balance were similar indicating that diet manipulation can alter water excretion way without water balance of animals. Nitrogen compounds absorbed and retained were similar $(P>0.05)$ among horses indicating that protein in the diets were adjusted.
\end{abstract}

Keywords: diets, feeds, nitrogen compounds.

\section{Introdução}

Nos eqüinos, a ingestão de água está relacionada com o consumo de matéria seca e à energia da dieta, enquanto sua excreção está associada ao conteúdo de proteínas, minerais e fibra da dieta. Fatores conhecidos que afetam a ingestão de água pelos eqüinos são: composição da dieta, temperatura e palatabilidade da água, atividade física e condições climáticas. Existe uma perda contínua de fluidos do corpo pelas fezes, urina, sudorese e evaporação pela respiração. Estas perdas têm que ser compensadas pela ingestão de água ou pela água presente nos alimentos da dieta (Cymbaluk, 1989).
O valor nutritivo de uma forragem normalmente refere-se à composição química da forragem, a sua digestibilidade e a natureza dos produtos da digestão (Reis e Rodrigues, 1993). A alfafa é considerada a forrageira padrão na nutrição de eqüinos devido ao seu elevado valor nutritivo, conhecida e cultivada em quase todo o mundo, sendo utilizada tanto em pastejo quanto na forma de feno e silagem pré-seca (Costa e Monteiro, 1997).

Dittrich et al. (1999), avaliando a preferência dos eqüinos pastejando diferentes espécies do gênero Cynodon: tifton85 , tifton- 68 , tifton-44, coast cross, grama estrela roxa e grama porto rico, verificaram maior número de bocados no tifton-85,

Parte da dissertação do primeiro autor apresentada ao Programa de Pós-graduação em Zootecnia da UFRRJ. Projeto de Pesquisa financiado pelo CNPq e FAPERJ

* Zootecnista. Discente de Mestrado em Zootecnia - UFRRJ

** Professor associado. UFRRJ. Bolsista Pesquisador CNPq e-mail: falmeida@ufrrj.br

Correspondência: Instituto de Veterinária - UFRRJ. BR 465, Km 7, Seropédica, RJ. 23890-000

*** Professor adjunto. DZO-CCA-UFES

**** Discente de graduação da UFRRJ. Bolsista de Iniciação Científica - FAPERJ

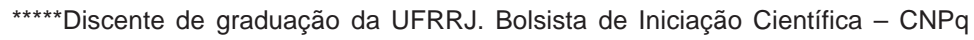


quando comparada às outras espécies de Cynodon, indicando maior palatabilidade por essa gramínea.

Diante do exposto, este trabalho teve como objetivo avaliar o balanço hídrico e de nitrogênio em eqüinos alimentados com dietas simples ou compostas por feno de alfafa, feno de tifton85 e rações concentradas.

\section{Material e métodos}

O experimento foi conduzido no Laboratório de Pesquisas em Saúde Eqüina da Universidade Federal Rural do Rio de Janeiro, no período de junho a agosto de 2004. Foram utilizados quatro potros mestiços, com peso vivo médio de $200 \pm 2,2 \mathrm{~kg}$, não castrados, com idade média de 30 meses.

As dietas foram formuladas considerando-se um consumo dietético diário equivalente a $2,0 \%$ do peso vivo dos animais, com base na matéria seca, de acordo com as recomendações do NRC (1989), sendo compostas por feno de capim tifton-85 (Cynodon dactilus) e feno de alfafa (Medicago sativa L.) como volumosos e rações concentradas, segundo as quatro dietas experimentais: Dieta I - composta por feno de tifton-85; Dieta II - composta por feno de alfafa e feno de tifton-85, na proporção 50:50; Dieta III - composta por 30\% de feno de tifton-85, 30\% de feno de alfafa e $40 \%$ de ração concentrada I; Dieta IV composta por $60 \%$ de feno de tifton- 85 e $40 \%$ de ração concentrada II (Tabela 1).

Tabela 1: Composição percentual dos ingredientes, teores de matéria seca (MS), matéria orgânica $(\mathrm{MO})$, energia bruta $(\mathrm{EB})$, proteína bruta $(\mathrm{PB})$, extrato etéreo (EE), fibra em detergente neutro (FDN), fibra em detergente ácido (FDA) e hemicelulose (HEM) expressos na base da matéria seca, nas dietas experimentais

\begin{tabular}{lcccc}
\hline & \multicolumn{3}{c}{ Dietas } \\
\cline { 2 - 5 } Ingredientes/ Nutrientes & Tifton-85 & Tifton-85 + alfafa & $\begin{array}{c}\text { Tifton-85 + alfafa + } \\
\text { Concentrado I }\end{array}$ & $\begin{array}{c}\text { Tifton-85 + } \\
\text { Concentrado II }\end{array}$ \\
\hline Feno de alfafa & - & 50,0 & 30,0 & - \\
Feno de Tifton-85 & 100 & 50,0 & 30,0 & 60,0 \\
Ração concentrada I & - & - & 40,0 & - \\
Ração concentrada II & - & - & - & 40,0 \\
Total & 100 & 100 & 100 & 100 \\
\hline M̄S (\%) & 83,9 & 84,3 & 84,9 & 94,4 \\
MO (\%) & 94,6 & 92,6 & 94,0 & 14,8 \\
PB (\%) & 12,5 & 14,2 & 14,1 & 3,5 \\
EE (\%) & 3,4 & 3,1 & 3,3 & 47,7 \\
FDN (\%) & 72,3 & 59,3 & 40,3 & 22,3 \\
FDA (\%) & 34,0 & 33,2 & 21,4 & 25,5 \\
HEM (\%) & 38,3 & 26,1 & 18,9 & 4,21 \\
EB (Mcal/kgMS) & 4,45 & 4,52 & 4,34 &
\end{tabular}

o animal na repetição considerado como unidade experimental. Cada período experimental teve duração de 20 dias, sendo 15 de adaptação às dietas, 5 de coleta de fezes e 1 dia de coleta de urina, procedida no $20^{\circ}$ dia.

Foi utilizado o método da coleta total de fezes utilizando bolsas apropriadas para eqüinos. A cada período de seis horas, as fezes de cada animal eram pesadas, e foi retirada uma amostra referente a $10 \%$ do peso total das fezes coletadas, sendo estas amostras mantidas sob refrigeração. Ao término de cada dia, as amostras de cada animal foram homogeneizadas e retirada uma amostra composta com aproximadamente $300 \mathrm{~g}$, sendo esta armazenada $\mathrm{a}-18^{\circ} \mathrm{C}$. Ao término de cada período, as amostras de cada animal foram descongeladas à temperatura ambiente, homogeneizadas e composta em apenas uma amostra por animal em cada período. Estas amostras foram pré-secas em estufa de ventilação forçada a $65^{\circ} \mathrm{C}$ por 72 horas e posteriormente moídas e acondicionadas em frascos plásticos etiquetados.

A água foi fornecida ad libitum em baldes de volumes conhecidos, renovados três vezes ao dia às 7, 13 e 19 horas, durante cinco dias e as sobras medidas diariamente às 7 horas, para o cálculo do consumo diário. No $20^{\circ}$ dia de cada período experimental, a urina foi colhida durante 24 horas, através de coletores de borracha, semelhantes aos descritos por Tasker (1966), durante um período de 12 horas, das 7 às 19 horas, quando a urina foi recolhida em recipientes plásticos contendo $25 \mathrm{~mL}$ de HCL $5 \mathrm{M}$, sendo coletada uma alíquota de $10 \%$, aproximadamente $100 \mathrm{~mL}$ de urina, que foi posteriormente armazenada $\mathrm{a}-18^{\circ} \mathrm{C}$, para a análise do nitrogênio total. Os valores de excreção urinária diária do nitrogênio foram obtidos somando e retirando-se a média dos valores de cada coleta.

O consumo total de água foi calculado pela soma da água livre consumida e a água presente no alimento. O total de água excretada na urina foi calculado através da análise do teor de matéria seca da urina e do teor de matéria seca das fezes.

O balanço hídrico foi avaliado utilizando as seguintes equações:
As dietas foram oferecidas às 7, 13, 19 e 1 horas, sendo a ração concentrada oferecida 20 minutos depois do volumoso. A água e o suplemento mineral foram fornecidos à vontade.

Foi utilizado o delineamento experimental em Quadrado Latino $4 \times 4$, com quatro tratamentos (dietas), quatro animais, sendo
- Consumo total de água (litros/dia) = água consumida + água consumida na dieta

- Excreção total de água (litros/dia) = água excretada na urina + água excretada nas fezes

- Balanço hídrico (litros/dia) = Consumo total água - excreção total de água 
O balanço de nitrogênio foi avaliado de acordo com as quantidades diárias dos compostos nitrogenados consumidos e excretados nas fezes e urina. As quantidades de compostos nitrogenados retidos e absorvidos foram calculadas utilizando as seguintes equações:

$-\mathrm{N}$ absorvido ( $\mathrm{g} /$ dia) $=\mathrm{N}$ consumido $(\mathrm{g})-\mathrm{N}$ fecal $(\mathrm{g})$

$-\mathrm{N}$ retido $(\mathrm{g} / \mathrm{dia})=\mathrm{N}$ consumido $(\mathrm{g})-\mathrm{N}$ fecal $(\mathrm{g})-\mathrm{N}$ urinário $(\mathrm{g})$

Nas amostras de urina foram efetuadas as análises para a determinação dos teores de MS e nitrogênio total, segundo metodologia descrita por Silva (1990).

Os valores obtidos do balanço hídrico e de nitrogênio foram submetidos à análise de variância e comparados pelo teste de Tukey, de $5 \%$ de probabilidade. As análises estatísticas foram procedidas utilizando-se o programa Sistema de Análises Estatísticas e Genéticas - SAEG (UFV, 2000).

\section{Resultados e discussão}

Os valores médios diários de consumo e excreção de água e do balanço hídrico em eqüinos consumindo as dietas experimentais estão na Tabela 2.
Cymbaluk (1989) e Oliveira et al. (2003) observaram consumo de água variando de 3,4 a 3,6 L/kg MS em eqüinos consumindo dietas exclusivas de feno de gramíneas, valores inferiores ao observado nos eqüinos consumindo dieta exclusiva com feno de tifton-85 ou dieta mista com feno de tifton-85 e alfafa.

No entanto, o consumo de água pelos eqüinos no presente trabalho é próximo das recomendações de Frape (1992), de 2 a 4 litros de água/kg de MS ingerida para eqüinos adultos em ambiente uniforme. O consumo também pode variar conforme o tipo de processamento do volumoso e da ração concentrada ingerida, isso porque o conteúdo mineral, fibroso e de outros componentes são diferentes entre os alimentos, afetando o consumo de água (Cunha, 1991).

Quanto à excreção de água, observou-se que os animais consumindo a dieta composta por feno de tifton-85 e feno de alfafa apresentaram excreção fecal de 7,93 litros de água/dia, valor maior $(P<0,05)$ do que os animais consumindo as demais dietas, cuja excreção fecal média de água foi de 4,99 litros de água/dia.

Oliveira et al. (2003), avaliando dietas para eqüinos com níveis crescentes de feno de coastcross, verificaram que o nível de

Tabela 2: Valores médios diários do consumo e excreção de água e do balanço hídrico e os respectivos coeficientes de variação (CV) dos eqüinos alimentados com as dietas experimentais

\begin{tabular}{lcccccc}
\hline & \multicolumn{5}{c}{ Dietas } \\
\cline { 2 - 6 } \multicolumn{1}{c}{ Água } & Tifton-85 & $\begin{array}{c}\text { Tifton-85 } \\
+ \text { alfafa }\end{array}$ & $\begin{array}{c}\text { Tifton-85 } \\
+ \text { alfafa + } \\
\text { Concentrado I }\end{array}$ & $\begin{array}{c}\text { Tifton- 85 + } \\
\text { Concentrado II }\end{array}$ & Média & CV (\%) \\
\hline Água consumida (L/dia) & & & $20,07^{\mathrm{a}}$ & $18,27^{\mathrm{a}}$ & - & 12,31 \\
Ingestão de água da dieta (L/dia) & $13,13^{\mathrm{b}}$ & $19,24^{\mathrm{a}}$ & $0,75^{\mathrm{a}}$ & $0,86^{\mathrm{a}}$ & 0,83 & 11,35 \\
Consumo total de água (L/dia) & $0,82^{\mathrm{a}}$ & $0,90^{\mathrm{a}}$ & $20,82^{\mathrm{a}}$ & $19,13^{\mathrm{a}}$ & - & 12,02 \\
Consumo total de água (L/kgMSdia) & $13,95^{\mathrm{b}}$ & $20,14^{\mathrm{a}}$ & $5,03^{\mathrm{a}}$ & $4,26^{\mathrm{a}}$ & 4,73 & 28,90 \\
Água excretada das fezes (L/dia) & $5,37^{\mathrm{a}}$ & $4,25^{\mathrm{a}}$ & $5,17^{\mathrm{b}}$ & - & 20,33 \\
Água excretada na urina (L/dia) & $4,28^{\mathrm{b}}$ & $7,93^{\mathrm{a}}$ & $5,51^{\mathrm{b}}$ & $3,78^{\mathrm{a}}$ & 3,48 & 31,28 \\
Excreção total de água (L/dia) & $2,03^{\mathrm{a}}$ & $4,32^{\mathrm{a}}$ & $3,79^{\mathrm{a}}$ & $8,95^{\mathrm{b}}$ & - & 14,93 \\
Balanço hídrico (L/dia) & $6,31^{\mathrm{c}}$ & $12,26^{\mathrm{a}}$ & $9,30^{\mathrm{b}}$ & $10,18^{\mathrm{a}}$ & 9,31 & 27,43 \\
\hline
\end{tabular}

Médias seguidas pela mesma letra, na linha, não diferem entre si, pelo Teste de Tukey $(P>0,05)$.

Os valores médios diários do consumo total de água nos eqüinos consumindo a dieta exclusiva com feno de tifton-85 foram menores $(P<0,05)$, cerca de 13,13 litros. Isto pode estar relacionado com o menor consumo de matéria seca. No entanto, considerando o consumo de água em relação à quantidade de matéria seca consumida, expresso em quilogramas, não se observaram diferenças $(P>0,05)$ entre os animais consumindo as dietas experimentais.

O valor médio diário de água consumida foi de 4,73 L/kg MS consumida, superior aos citados pelo NRC (1989), em eqüinos consumindo dietas exclusivas de feno, de cerca de 3,6 L/kg MS consumida, enquanto que eqüinos consumindo dietas compostas por feno e concentrado o consumo estimado é de 2,9 L/kg MS consumida, recomendando o consumo de 2 a 3 litros de água/kg de MS consumida. volumoso na dieta não afetou o consumo de água. No entanto, a excreção de água nas fezes foi aumentada com a inclusão dietética do volumoso, influenciando o balanço hídrico.

A excreção de água pela urina não diferiu entre os animais consumindo as diferentes dietas $(P>0,05)$, observando-se valor médio diário de 3,48 litros de água excretada via urina. Considerando a excreção total diária de água, verificou-se que houve diferença $(P<0,05)$ entre os animais consumindo diferentes dietas com menor excreção nos eqüinos alimentados com a dieta exclusiva com feno de tifton-85, de 6,31 litros e, maior excreção nos animais consumindo dieta composta por feno de tifton-85 e alfafa, de 12,26 litros.

Segundo Almeida et al. (1997), a urina é a principal via de excreção dos compostos nitrogenados consumidos excessivamente, considerando o nível de proteína bruta reco- 
mendado para mantença, de 10,4\% (NRC, 1989). Meyer et al. (1985) citam que o metabólito de maior excreção na urina é a uréia proveniente do metabolismo hepático da amônia absorvida no intestino grosso e oriunda do catabolismo dos aminoácidos.

A maior excreção de nitrogênio urinário eleva a excreção de água por esta via, indicando que os eqüinos consumindo as dietas com inclusão de alfafa, com maiores teores de proteína bruta, aumentam a excreção de nitrogênio e água na urina. Estudos relatam que eqüinos alimentados com feno de alfafa excretam água primariamente pela urina (Groenendyk e English, 1988).

Em relação ao balanço hídrico dos animais, não houve diferença entre os animais consumindo as diferentes dietas ( $P>0,05)$, observando-se um valor médio diário de 9,31 litros/ dia. Segundo Oliveira et al. (2003), o balanço hídrico em eqüinos consumindo dietas com maior proporção de concentrado retém mais água no organismo do que as dietas que contêm mais volumoso; no entanto, tal fato não foi observado no presente trabalho.

Os valores das quantidades dos compostos nitrogenados consumidos, excretados nas fezes e urina, absorvidos e retidos nos eqüinos alimentados com as dietas experimentais estão apresentados na Tabela 3.

Os eqüinos alimentados com dieta exclusiva de feno de tifton85 consumiram menores quantidades de $\mathrm{N}$, de $68,04 \mathrm{~g} / \mathrm{dia}$, em relação aos animais consumindo as demais dietas, estando relacionado com os percentuais de PB nas dietas experimentais. Meyer (1987) observou que as dietas para eqüinos geralmente contêm mais proteína do que o necessário para atender aos requerimentos nutricionais.

Considerando a excreção fecal de nitrogênio, observa-se menor excreção fecal diária nos eqüinos consumindo a dieta exclusiva com feno de tifton-85, de 20,72g de nitrogênio, e maiores valores nos animais consumindo as dietas com a inclusão de alfafa de 36,78 e $32,17 \mathrm{~g}$ na dieta composta por feno de tifton-85 e alfafa e na dieta composta por feno de tifton-85, alfafa e concentrado, respectivamente.

Em relação à excreção urinária de compostos nitrogenados, verificou-se maior excreção diária de nitrogênio nos animais consumindo a dieta com maior percentual de inclusão de alfafa de $65,74 \mathrm{~g}$ de nitrogênio, indicando ser a urina a principal excreção dos compostos nitrogenados consumidos excessivamente, em acordo com a maior excreção de água pelos animais que consumiram alfafa, indicando que a excreção de $\mathrm{N}$ aumenta a excreção de água. Freeman et al. (1988), avaliando o balanço de nitrogênio em cavalos em atividade física, observaram aumento da excreção urinária de $\mathrm{N}$ quando a quantidade de $\mathrm{N}$ ingerido foi aumentada.

As quantidades diárias de compostos nitrogenados absorvidos e compostos nitrogenados retidos não diferiram $(P>0,05)$ entre os animais consumindo as diferentes dietas, com valores médios de 64,88 e 14,33g, respectivamente, compostos nitrogenados absorvidos e retidos pelos eqüinos. OsIman et al. (2004) avaliando eqüinos adultos, observaram que as excreções de nitrogênio urinário e fecal, assim como a absorção de nitrogênio não foram influenciadas pela dieta, o que pode indicar que os animais ajustam o consumo de proteína dietética.

\section{Conclusões}

A manipulação da dieta pode alterar a via de excreção de água sem afetar o balanço hídrico dos animais.

Os animais consumindo dieta exclusiva com feno de tifton-85 apresentaram menores valores de excreção fecal e urinária de compostos nitrogenados, sem afetar as quantidades de compostos nitrogenados absorvidos e retidos, indicando o ajuste no consumo da proteína dietética entre as diferentes dietas.

Tabela 3: Quantidades médias dos compostos nitrogenados $(\mathrm{N})$ consumido, $\mathrm{N}$ fecal, $\mathrm{N}$ urinário, $\mathrm{N}$ retido, $\mathrm{N}$ absorvido por eqüinos alimentados com diferentes dietas e os respectivos coeficientes de variação $(\mathrm{CV})$

\begin{tabular}{lccccc}
\hline \multirow{2}{*}{ Nitrogênio (N) } & \multicolumn{5}{c}{ Dietas } \\
\cline { 2 - 5 } & Tifton-85 & Tifton-85 + alfafa & $\begin{array}{c}\text { Tifton-85 + alfafa }+ \\
\text { concentrado I }\end{array}$ & $\begin{array}{c}\text { Tifton-85 + } \\
\text { concentrado II }\end{array}$ & CV (\%) \\
\hline N consumido (g/dia) & $68,04^{\mathrm{b}}$ & $109,21^{\mathrm{a}}$ & $93,61^{\mathrm{a}}$ & $109,36^{\mathrm{a}}$ & 18,2 \\
$\mathrm{~N}$ fecal (g/dia) & $20,72^{\mathrm{c}}$ & $36,78^{\mathrm{a}}$ & $32,17^{\mathrm{ab}}$ & $27,56^{\mathrm{b}}$ & 10,2 \\
$\mathrm{~N}$ urinário (g/dia) & $25,18^{\mathrm{b}}$ & $65,74^{\mathrm{a}}$ & $51,16^{\mathrm{ab}}$ & $53,59^{\mathrm{ab}}$ & 28,8 \\
N absorvido (g/dia) & $47,31^{\mathrm{a}}$ & $68,97^{\mathrm{a}}$ & $61,44^{\mathrm{a}}$ & $81,81^{\mathrm{a}}$ & 26,4 \\
$\mathrm{~N}$ retido (g/dia) & $12,13^{\mathrm{a}}$ & $6,70^{\mathrm{a}}$ & $10,28^{\mathrm{a}}$ & $28,21^{\mathrm{a}}$ & 110,1 \\
\hline
\end{tabular}

Médias seguidas pela mesma letra, na linha, não diferem entre si pelo Teste de Tukey $(P>0,05)$. 


\section{Referências}

ALMEIDA, F.Q.; VALADARES FILHO, S.C.; CECON, P.R.; LEÃO, M.I.; DONZELE, J.L.; SILVA, J.F.C.; QUEIROZ, A.C. Compostos nitrogenados endógenos pré-cecal, pós-ileal, fecal e urinário em eqüinos. Rev. Bras. Zootec., v. 26, n. 3, p. 538-545,1997.

COSTA, C.; MONTEIRO, A.L.G. Alfafa como forrageira para corte e pastejo. SIMPÓSIOSOBRE ECOSSISTEMADE PASTAGENS, 3., 1997 Jaboticabal, Brasil. Anais... FCAV/UNESP 1997. p. 297-317.

CUNHA, T.J. Horse feeding and nutrition. 2. ed. San Diego, California: Academic Press, 1991, 445 p.

CYMBALUK, N.F. Water balance of horses fed various diets. Eq. Pract., v.11, n.1, p.19-24, 1989.

DITTRICH, J.R.; CARVALHO, P.C.F.; MORAES, A.; PRACHE, S.; LUSTOSA, S.B.C.; SILVEIRA, E.O. Preferência e profundidade de bocado de eqüinos em diferentes gramíneas do gênero Cynodon,37. In: REUNIÃO ANUAL DA SOCIEDADE BRASILEIRA DE ZOOTECNIA. Botucatu. Anais...RBZ:1998, p. 656-658.

FRAPE, D.L. Equine nutrition and feeding. Harlow: Longman Scientific Technical, 1992. $373 p$.

FREEMAN, D.W.;POTTER, G.D.; SCHELLING, G.T. Nitrogen metabolism in mature horses at varying levels of work. J. Anim. Sci., v. 66, p. 407412, 1988.

GROENENDYK, S.; ENGLISH, P.B. External balance of water and electrolytes in the horse. Eq. Vet. J., v. 20, p. 189-193, 1988.

MEYER, H.; VON STEIN, S.; SCHMIDT, M. Investigations to determine endogenous faecal and renal losses in horses. In: EQUINE NUTRITION AND PHYSIOLOGY SOCIETY SYMPOSIUM, 9., 1985, Michigan. Proceedings... East Lansing, 1985, p. 68-72.
MEYER, H.P. Postprandial renal and faecal water and electrolyte excretion in horses in relation to kind of feedstuffs, amount of sodium ingested and exercise. In: EQUINE NUTRITION AND PHYSIOLOGY SOCIETY SYMPOSIUM, 10., 1987. Proceedings...ENPS. 1987, p. 6772.

NATIONAL RESEARCH COUNCIL - NRC. Nutrient requirements of horses., 5. ed. Washington, D.C., 1989. 100 p.

OLIVEIRA, C.A.A.; ALMEIDA, F.Q.; VIEIRA, A.A.; LANA, A.M.Q.; MACEDO, R.; LOPES, B.A.; CORASSA, A. Cinética de passagem da digesta, balanço hídrico e de nitrogênio em eqüinos consumindo dietas com diferentes proporções de volumosos e concentrado. Rev. Bras. Zootec., v. 32, n. 1, p. 145-149, 2003.

OLSMAN, A.F.S.; HUURDEMAN, W.L.; JANSEN, J.; HAAKSMA, J.J; SLOET, BEYNEN, A.C. Macronutrient digestibility, nitrogen balance, plasma indicators of protein metabolism and mineral absorption in horses fed a ration rich in sugar beet pulp. J. An. Physiol. and Nutr., n. 88, p. 231-331, 2004.

REIS, R.A.; RODRIGUES, L.R.A. Valor nutritivo de plantas forrageiras. Jaboticabal-UNESP - FUNEP. 26 p. 1993.

SILVA, D.J. Análises de alimentos - métodos químicos e biológicos. 2. ed. Viçosa, UFV: Imprensa Universitária, 1990, 166 p.

TASKER, J.B. Fluid and electrolyte studies in the horse II: Apparatus for the collection of total daily urine and faeces from horses. Cornell Vet., v. 56, n. 1, p. 189-197, 1966.

UNIVERSIDADE FEDERAL DE VIÇOSA. SAEG - Sistema de análises estatísticas e genéticas. Viçosa: Universidade Federal de Viçosa, 2000. Manual do usuário, 150 p. 